\title{
Aberrant expression of circulating Th17, Th1 and Tc1 cells in patients with active and inactive ulcerative colitis
}

\author{
ZHAOGANG DONG ${ }^{1}$, LUTAO DU ${ }^{1}$, XIAOFEI XU ${ }^{2}$, YONGMEI YANG ${ }^{1}$,

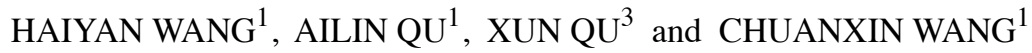 \\ Departments of ${ }^{1}$ Clinical Laboratory, ${ }^{2}$ Obstetrics and Gynecology, ${ }^{3}$ Institute of Basic Medical Sciences, \\ Qilu Hospital, Shandong University, Jinan, Shandong 250012, P.R. China
}

Received December 10, 2012; Accepted February 1, 2013

DOI: $10.3892 /$ ijmm.2013.1287

\begin{abstract}
Ulcerative colitis (UC) is a chronic relapsing inflammatory bowel disease, yet its etiology and pathogenesis remain poorly understood. The aberrant expression of $\mathrm{T}$ lymphocytes plays an essential role in the progression of UC. This study aimed to evaluate the expression profile of circulating Th17, Th1 and Tc1 cells in patients with active and inactive UC. Our results revealed that the percentage of circulating Th17 cells $\left(\mathrm{CD}^{+} \mathrm{CD} 8{ }^{-} \mathrm{IL}-17^{+}\right)$was significantly increased in patients with active UC when compared with the percentage in patients with inactive UC, Crohn's disease (CD) and healthy controls. The percentages of circulating Th1 $\left(\mathrm{CD} 3{ }^{+} \mathrm{CD} 8-\mathrm{IFN}-\gamma^{+}\right)$and $\mathrm{Tc} 1\left(\mathrm{CD} 3{ }^{+} \mathrm{CD} 8{ }^{+} \mathrm{IFN}-\gamma^{+}\right)$cells were also higher in patients with active UC when compared with the percentages in patients with inactive UC and normal controls, although levels were lower than that in $\mathrm{CD}$. Further analysis showed that Th17 cells were positively correlated with Th1 cells, but not with Tc1 cells. Notably, the three cells had a positive correlation with disease activity, extent of disease, detection of erythrocyte sedimentation rate and c-reactive protein in active UC. Moreover, plasma IL-17 was higher in patients with active UC, and a similar trend applied to the mRNA levels of ROR $\gamma \mathrm{t}$ and T-bet in peripheral blood mononuclear cells (PBMCs). The levels of p-STAT3 and p-STAT5 in PBMCs, as well as the ratio of p-STAT3/pSTAT5, were also elevated in active UC patients. Taken together, our findings revealed that elevated circulating Th17, Th1 and Tc1 cells and the aberrant activation of the STAT pathway may be implicated in the progression of UC. These findings may provide preliminary experimental clues for the development of new therapies for UC.
\end{abstract}

Correspondence to: Professor Chuanxin Wang, Department of Clinical Laboratory, Qilu Hospital, Shandong University, 107 Wenhuaxi Road, Jinan, Shandong 250012, P.R. China

E-mail: cxwang@sdu.edu.cn

Key words: ulcerative colitis, T helper 17, T helper 1, T cytotoxic 1, signal transducer and activator of transcription 3, signal transducer and activator of transcription 5

\section{Introduction}

Ulcerative colitis (UC), a chronic relapsing inflammatory bowel disease (IBD) restricted to the large bowel, is a major public health threat worldwide, particularly in China $(1,2)$. UC is characterized by periods of remission punctuated by clinical exacerbations and frequent relapses. Moreover, $1 \%$ of UC cases with extensive disease of long duration progress to colorectal cancer (CRC) (3). A previous study revealed that the immune response plays an important role in the pathophysiology of UC (4), and a cytokine profile with dysregulation of both Th1 [producing interferon- $\gamma($ IFN- $\gamma)$ ] and Th2 [producing interleukin-4 (IL-4)] is implicated in the development of UC (5-7). However, it is still unresolved whether a Th1- or Th2-type of immune response dominates in UC.

Research has demonstrated that $\mathrm{UC}$ is an atypical Th2 response, and levels of Th1 cytokines (such as IFN- $\gamma$ mRNA) in colonic lamina propria $\mathrm{T}$ lymphocytes $\left(\mathrm{CD}^{+} \mathrm{LPL}\right)$ are reduced (7). However, an abnormality in IL-4 is not observed in UC $(7,8)$, and Th2-related cytokines do not appear to be useful as predictive markers in relation to the outcome of UC patients treated with infliximab (9). Therefore, the Th2 immune response has not been conclusively demonstrated in UC. Other studies have shown that tumor necrosis factor- $\alpha$ (TNF- $\alpha$; a Th1-cytokine) and other cytokines, such as IFN- $\gamma$ and IL-6, are expressed at a high level in blood samples or colonic mucosa (10-14), suggesting that a higher Th1 response may be closely associated with the development of UC. One possible explanation for this discrepancy may be that in addition to the local immune response, circulating $\mathrm{T}$ lymphocytes in peripheral blood mononuclear cells (PBMCs) and cytokines may also contribute to this inconsistency, since our previous studies revealed that circulating $\mathrm{T}$ lymphocytes are elevated and implicated in the pathogenesis of several autoimmune diseases, including rheumatoid arthritis and immune thrombocytopenic purpura $(15,16)$. However, the expression profile of circulating $\mathrm{T}$ lymphocytes and related cytokines in UC remains unclear.

Similar to $\mathrm{CD}^{+} \mathrm{T}$ (Th) lymphocytes, $\mathrm{CD} 8^{+} \mathrm{T}(\mathrm{Tc})$ lymphocytes may also be functionally subdivided into mutually exclusive type 1 (T1) and type 2 (T2) subsets based on the secretion of either IFN- $\gamma$ or IL-4 (15). Tc cells are able to kill target cells directly, and are involved in several autoimmune 
diseases. However, to date, no data exist concerning the Tc cell profile in UC. In addition, recent findings of a newly identified $\mathrm{CD}^{+}{ }^{+}$Th cell subset, known as Th17 cells, may shed light on the study of the Th17-mediated immune response in UC (17-19). Th17 cells are characterized as preferential producers of several cytokines, such as IL-17A (also termed IL-17), IL-17F, IL-21, IL-22 and IL-6, and may have evolved for host protection against the microbes for which Th1 or Th2 immunity are not well suited (20). Just as T-bet controls the Th1 lineage, the activity of the transcription factor retinoic acid-related orphan receptor- $\gamma \mathrm{t}(\mathrm{ROR} \gamma \mathrm{t})$ is required for Th17 cell differentiation (21). ROR $\gamma \mathrm{t}$ may be activated by IL-6 and IL-23, and consequently enhances Th17 cell development by signal transducer and activator of transcription 3/suppressor of cytokine signaling 3 (STAT3/SOCS3) in UC and UC-induced carcinogenesis (22-24). Moreover, the STAT3 level has been found to be associated with aggravation of UC (25). All of these data suggest that the ROR $\gamma$ t-STAT3-Th17 pathway plays an important role in the progression of UC.

The basis for new biological therapy requires new knowledge of immunological molecules that mediate immune disorders (26). Therefore, from a clinical point of view, it is essential to understand the immune status of UC. To further investigate the role of circulating Th17, Th1 and Tc1 cells in the pathogenesis of UC, we examined the levels of circulating Th17, Th1 and Tc1 cells, and analyzed their correlation with clinicopathological features. Moreover, the roles of ROR $\gamma \mathrm{t}$ and STAT pathways in the progression of UC were also evaluated.

\section{Materials and methods}

Patients and specimens. Fifty-five patients with active UC (24 males, age range 31-72 years, median age 57 years and 31 females, age range 32-68 years, median age 53 years) and 21 patients with $\mathrm{UC}$ in remission $(9$ males, age range 28-65 years, median age 51 years and 12 females, age range 31-70 years, median age 55 years) were enrolled in this study between August 2008 and June 2010 at the Department of Gastroenterology, Qilu Hospital, Shandong University (Shandong, China). Patients with active UC were diagnosed according to routine clinical, endoscopic and histopathological features (27). Patient WBC counts ranged from 8.3 to $14.8 \times 10^{9} / 1$ with a median count of $11.6 \times 10^{9} / 1$. The clinical characteristics of the patients are summarized in Table I. The Ulcerative Colitis Disease Activity Index (UCDAI; score 0-12) was employed to evaluate the degree of UC, as previously described (28-30). Patients in remission were enrolled in the study according to previously described criteria (29). Of the patients in remission, 5 patients had received no medication 6 weeks prior to sampling, 10 patients received only 5-aminosalicylic acid, and 6 patients received a combination of prednisolone and 5-aminosalicylic acid. In order to exclude any potential bias caused by the influence of medicine, patients receiving 5-aminosalicylic acid or 6-mercaptopurine/ azathioprine therapies were excluded if the dose had been altered within 30 days or within 3 months, respectively. In addition, we also recruited patients with Crohn's disease (CD) (7 males and 9 females, age range 25-59 years, median 43 years). Twenty-three healthy volunteers (9 males and 14 females, age range 23-68 years, median age 49 years) with no history of IBD nor other autoimmune diseases were recruited as healthy controls. Their WBC counts ranged from 4.1 to $8.7 \times 10^{9} / 1$ with a median count of $6.2 \times 10^{9} / 1$.

Venous blood samples of all subjects were collected in heparin-containing tubes. At the same time, plasma was collected by centrifugation at $4^{\circ} \mathrm{C}(3,000 \times \mathrm{g}$ for $10 \mathrm{~min})$, and then stored at $-80^{\circ} \mathrm{C}$ until use. The research protocol was approved by the Medical Ethics Committee of Qilu Hospital, Shandong University, and written informed consent was obtained from all subjects prior to conducting the study.

Antibodies and reagents. Phorbol myristate acetate (PMA), ionomycin and monensin were from eBioscience (San Diego, CA, USA). Ficoll-Paque was from Pharmacia Diagnostics (Uppsala, Sweden). PE-Cy5-conjugated anti-CD3, FITCconjugated anti-CD8, PE-conjugated IL17A or IFN- $\gamma$ monoclonal antibodies were purchased from eBioscience. Anti-human phospho-STAT3, anti-human STAT3, anti-human phospho-STAT5 and anti-STAT5 antibodies were purchased from Cell Signaling Technology, Inc. (Boston, MA, USA).

Flow cytometric analysis. Intracellular cytokines were assessed via flow cytometry to reflect cytokine-producing cells, as previously described $(15,31)$. Briefly, heparinized peripheral whole blood $(400 \mu \mathrm{l})$ was incubated with RPMI-1640 medium (1:1) at $37^{\circ} \mathrm{C}$ in $5 \% \mathrm{CO}_{2}$ for $4 \mathrm{~h}$ in the presence of PMA $(25 \mathrm{ng} / \mathrm{ml})$, ionomycin $(1 \mu \mathrm{g} / \mathrm{ml})$ and monensin $(1.7 \mu \mathrm{g} / \mathrm{ml})$. PMA and ionomycin are pharmacological $\mathrm{T}$ cell-activating agents. They have the advantage of stimulating $\mathrm{T}$ cells of any antigen specificity and may mimic signals generated by the TCR complex. Monensin may lead to an accumulation of cytokines in the cells since it blocks intracellular transport mechanisms.

The cells were stained with anti-CD3 labeled with PE-Cy5 and anti-CD8 labeled with FITC at room temperature in the dark for $15 \mathrm{~min}$. $\mathrm{CD}^{+}{ }^{+} \mathrm{CD} 8^{-} \mathrm{T}$ cells were used to delimitate $\mathrm{CD}^{+} \mathrm{T}$ cells as CD4 is down-modulated when cells are activated by PMA (32). After three washes with PBS, the cells were further stained with anti-IL-17A labeled with PE for Th17 detection or anti-IFN- $\gamma$ labeled by PE for Th1 or Tc1 detection after fixation and permeabilization according to the manufacturer's instructions. Isotype controls were used to correct compensation and confirm antibody specificity. After another three washes, cells were suspended in PBS and then immediately analyzed by flow cytometry (FACScan, BD Biosciences Pharmingen). Data from 10,000 events was acquired and analyzed by the software WinMDI 2.8 .

RNA extraction and quantitative real-time PCR assay. Ten milliliters of peripheral blood was obtained from all subjects, and PBMCs were isolated by gradient centrifugation on FicollPaque. PBMCs were then applied to an RNeasy mini-column (Qiagen GmbH, Hilden, Germany) and processed according to the manufacturer's instructions. The concentration of RNA was determined using an Eppendorf Biophotometer (Brinkmann Instruments, Westbury, NY, USA).

For reverse transcription-PCR, $1 \mu \mathrm{g}$ of total RNA was converted to cDNA using a reverse transcription kit (Fermentas Life Science, USA) in a $20 \mu \mathrm{l}$ volume. For quantitative real-time PCR, cDNA was amplified in triplicate 
Table I. Relationship between circulating Th17, Th1, Tc1 cells and clinicopathological variables in the patients with active ulcerative colitis.

\begin{tabular}{|c|c|c|c|c|c|c|c|}
\hline Parameters & $\mathrm{n}$ & Th17 (\%) & P-value & Th1 (\%) & P-value & $\mathrm{Tc} 1(\%)$ & P-value \\
\hline \multicolumn{8}{|l|}{ Age (years) } \\
\hline$<50$ & 30 & $2.97(2.42-3.53)$ & \multirow[t]{2}{*}{0.787} & $14.00(11.10-16.90)$ & \multirow[t]{2}{*}{0.837} & $15.69(9.21-22.17)$ & \multirow[t]{2}{*}{0.864} \\
\hline$\geq 50$ & 25 & $3.07(2.71-3.43)$ & & $13.37(10.84-14.90)$ & & $15.24(10.18-20.30)$ & \\
\hline \multicolumn{8}{|l|}{ Gender } \\
\hline Male & 24 & $3.01(2.41-3.61)$ & \multirow[t]{2}{*}{0.575} & $14.35(8.03-18.77)$ & \multirow[t]{2}{*}{0.773} & $14.91(10.65-19.17)$ & \multirow[t]{2}{*}{0.441} \\
\hline Female & 31 & $3.05(2.53-3.58)$ & & $16.49(12.10-20.88)$ & & $15.69(8.74-22.64)$ & \\
\hline \multicolumn{8}{|l|}{ Disease duration } \\
\hline$<10$ years & 38 & $2.95(2.53-3.38)$ & \multirow[t]{2}{*}{0.334} & $14.25(9.65-18.85)$ & \multirow[t]{2}{*}{0.382} & $14.29(8.47-20.10)$ & \multirow[t]{2}{*}{0.084} \\
\hline$\geq 10$ years & 17 & $3.18(2.59-3.77)$ & & $16.43(12.63-20.23)$ & & $15.24(10.18-20.30)$ & \\
\hline \multicolumn{8}{|l|}{ No. of relapses } \\
\hline$<5$ & 27 & $3.05(2.72-3.39)$ & \multirow[t]{2}{*}{0.73} & $17.00(10.57-24.29)$ & \multirow[t]{2}{*}{0.537} & $14.29(8.29-20.29)$ & \multirow[t]{2}{*}{0.644} \\
\hline$\geq 5$ & 28 & $3.06(2.60-3.52)$ & & $15.32(11.82-18.82)$ & & $15.69(11.32-20.07)$ & \\
\hline \multicolumn{8}{|l|}{ Disease activity } \\
\hline Mild + moderate & 37 & $2.81(2.48-3.14)$ & \multirow[t]{2}{*}{$0.007^{\mathrm{b}}$} & $14.38(7.38-21.38)$ & \multirow[t]{2}{*}{$0.014^{\mathrm{a}}$} & $14.91(10.36-19.46)$ & \multirow[t]{2}{*}{$0.016^{\mathrm{a}}$} \\
\hline Severe & 18 & $3.48(2.89-4.07)$ & & $17.41(11.35-21.47)$ & & $17.35(10.17-24.53)$ & \\
\hline \multicolumn{8}{|l|}{ Extent of diseases } \\
\hline Proctosigmoiditis & 18 & $2.87(2.07-3.67)$ & \multirow[t]{3}{*}{$0.001^{\mathrm{b}}$} & $14.70(9.28-20.12)$ & \multirow[t]{3}{*}{$0.002^{\mathrm{b}}$} & $15.89(12.26-19.52)$ & \multirow[t]{3}{*}{0.117} \\
\hline Left-sided colitis & 25 & $2.86(2.36-3.36)$ & & $18.01(14.35-21.67)$ & & $14.73(12.12-19.34)$ & \\
\hline Total colitis & 12 & $3.65(3.17-4.13)$ & & $21.87(17.47-26.27)$ & & $16.70(11.37-22.03)$ & \\
\hline \multicolumn{8}{|l|}{$\operatorname{ESR}(\mathrm{mm} / \mathrm{h})$} \\
\hline$<20$ & 26 & $2.24(1.81-2.67)$ & \multirow[t]{2}{*}{$0.001^{\mathrm{b}}$} & $13.44(11.32-15.56)$ & \multirow[t]{2}{*}{$0.010^{\mathrm{a}}$} & $17.04(12.52-21.56)$ & \multirow[t]{2}{*}{0.531} \\
\hline$\geq 20$ & 29 & $3.46(3.02-3.90)$ & & $16.48(10.08-22.16)$ & & $15.86(12.35-19.37)$ & \\
\hline \multicolumn{8}{|l|}{$\mathrm{CRP}(\mathrm{mg} / \mathrm{l})$} \\
\hline$<25$ & 31 & $2.73(2.24-3.22)$ & \multirow[t]{2}{*}{$0.005^{\mathrm{b}}$} & $12.75(9.54-15.96)$ & \multirow[t]{2}{*}{$0.001^{\mathrm{b}}$} & $14.21(10.01-18.21)$ & \multirow[t]{2}{*}{0.358} \\
\hline$\geq 25$ & 26 & $3.13(2.81-3.45)$ & & $16.12(11.35-20.89)$ & & $16.06(10.23-21.89)$ & \\
\hline
\end{tabular}

Data are expressed as median (interquartile range). ${ }^{a} \mathrm{P}<0.05$; ${ }^{\mathrm{b}} \mathrm{P}<0.01$. ESR, erythrocyte sedimentation rate; CRP, c-reactive protein.

in the LightCycler 2.0 (Roche), with SYBR-Green Real-Time PCR Master Mix (Toyobo Co., Ltd.) and primers for T-bet or ROR $\gamma$ t. GAPDH served as the internal standard. The average cycle threshold $(\mathrm{Ct})$ value of triplicate wells with each primer set was calculated as the amount of gene product present in the sample. The relative gene expression level was determined by the ratio between the $\mathrm{Ct}$ value for the target genes and GAPDH. The cycling conditions were as following: pre-denaturation for $30 \mathrm{sec}$ at $95^{\circ} \mathrm{C}$ followed by 40 cycles of $5 \mathrm{sec}$ at $95^{\circ} \mathrm{C}$ and $30 \mathrm{sec}$ at $60^{\circ} \mathrm{C}$. The primers are as follows: T-bet forward, GTGCTCCAGTCCCTCCATA and reverse, TCAGCTGAGTAATCTCGGCA (product size, 166 bp); ROR $\gamma \mathrm{t}$ forward, GCTGGTTAGGATGTGCCG and reverse, GGATGCTTTGGCGATGA (product size, 310 bp); GAPDH forward, GGTGGTCTCCTCTGACTTCAACAG and reverse, GTTGCTGTAGCCAAATTCGTTGT (product size, 126 bp).

Western blot analysis. PBMCs were isolated using FicollPaque and lysed on ice. Total protein $(30 \mu \mathrm{g})$ was separated by $10 \%$ sodium dodecyl sulfate polyacrylamide gels and then transferred onto nitrocellulose membranes. The membranes were incubated with the primary antibody $(1: 1,000)$ overnight at $4^{\circ} \mathrm{C}$. The specific horseradish peroxidase-conjugated goat anti-rabbit or goat anti-mouse secondary antibody was used to blot the target proteins, and the immunoreactivity of target proteins was detected using an enhanced chemiluminescence (ECL) detection kit.

Enzyme-linked immunosorbent assay (ELISA). The ELISA assay was performed on the plasma of all subjects. The plasma levels of IL-17 and IFN- $\gamma$ were determined using commercial ELISA kits (IL-17; R\&D Systems, Minneapolis, MN, USA and IFN- $\gamma$; Jingmei, Beijing, China) according to the manufacturer's instructions.

Detection of erythrocyte sedimentation rate (ESR) and $C$-reactive protein $(C R P)$. ESR was measured via the Westergren method. Plasma CRP was detected via the rate as determined by nephelometry according to the manufacturer's instructions. Positive and negative controls were used.

Statistical analysis. Data are mainly presented as means \pm SD. The SPSS software package (version 13.0; SPSS Inc., Chicago, IL, USA) was used for all statistical analyses. The distribution 
A

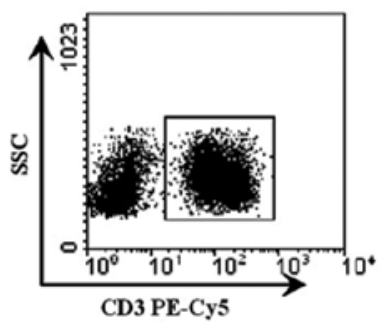

C

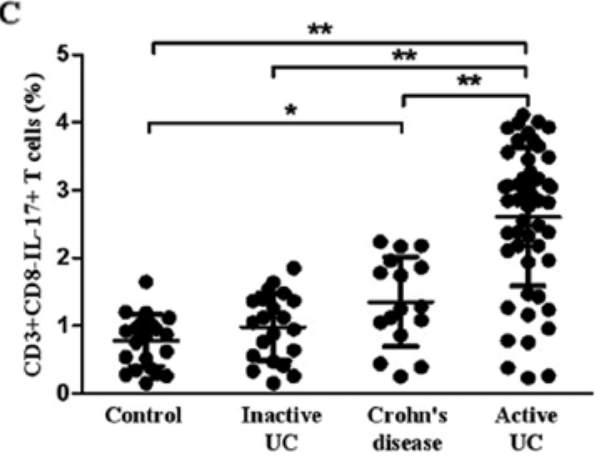

B

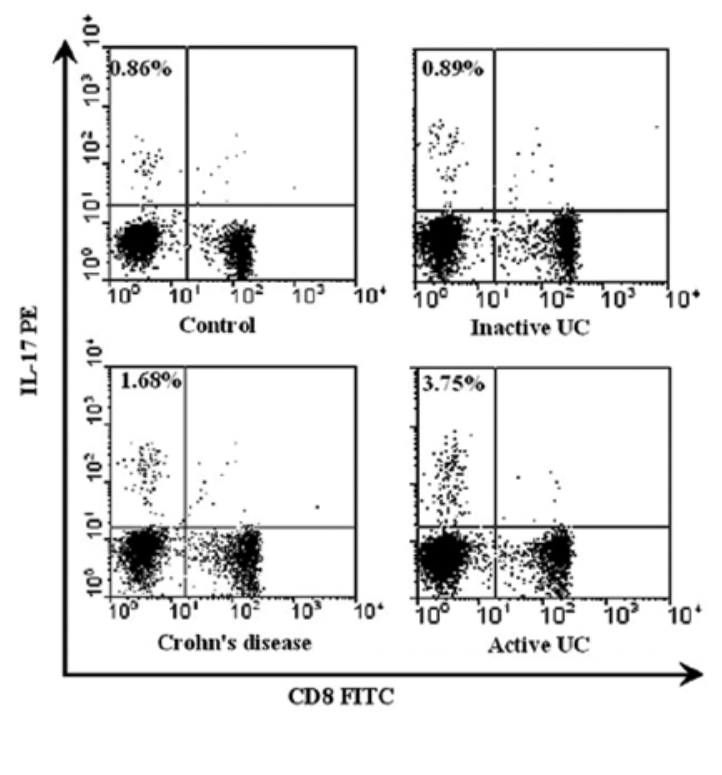

Figure 1. The percentage of circulating Th17 cells was increased in patients with active UC when compared with the percentages in patients with inactive UC, $\mathrm{CD}$ and healthy controls. Heparinized peripheral whole blood from all subjects was stimulated with PMA, ionomycin and monensin for 4 h, and then stained with labeled antibodies as described in Materials and methods. (A) CD3 ${ }^{+} \mathrm{T}$ subsets were gated by flow cytometry; the plots in ithe ntern box represent $\mathrm{CD} 3^{+}$ T cells. (B) Representative IL-17 expression in $\mathrm{CD}^{+}{ }^{+} \mathrm{CD}^{-} \mathrm{T}$ subsets (CD4 ${ }^{+} \mathrm{T}$ subsets) from each group is shown. (C) The level of Th17 cells of all subjects in the four groups. ${ }^{*} \mathrm{P}<0.05$ and ${ }^{* *} \mathrm{P}<0.01$. UC, ulcerative colitis.

of the samples was assessed by the Kolmogorov-Smirnov test. Pearson correlation test was applied to analyze the correlation of Th17, Th1 and Tc1 cells. Other experimental data were analyzed by Kruskal-Wallis test or Mann-Whitney $\mathrm{U}$ test wherever appropriate. Tukey post-hoc comparison was performed when statistical significance $(\mathrm{P}<0.05)$ was found between observations.

\section{Results}

Alteration of the level of circulating Th17 cells in patients with active and inactive UC. Our previous studies indicated that the level of Th17 cells is elevated in several autoimmune diseases, including rheumatoid arthritis and immune thrombocytopenic purpura $(15,16)$. To investigate the alteration in circulating Th17 cells in UC, we analyzed the expression of IL-17 in T cells by flow cytometry, based on cytokine patterns after in vitro stimulation by PMA/ionomycin in short-term culture. Fig. 1A and B shows a representative dot plot of IL-17 gated on $\mathrm{CD}^{+} \mathrm{T}$ cells in patients with active $\mathrm{UC}$, inactive UC, CD and controls. As shown in Fig. 1C, the percentage of circulating Th17 cells $\left(\mathrm{CD} 3{ }^{+} \mathrm{CD} 8-\mathrm{IL}-17^{+} \mathrm{T}\right.$ cells) was significantly elevated in patients with active UC $(2.90 \pm 0.73 \%)$ compared with that in inactive UC $(0.98 \pm 0.49 \%, \mathrm{P}<0.001)$, CD $(1.46 \pm 0.67 \%, P=0.008)$ and healthy controls $(0.87 \pm 0.47 \%$, $\mathrm{P}<0.001)$. Patients with CD displayed an increased percentage of Th17 cells when compared with that of the healthy controls $(\mathrm{P}=0.014)$. However, there was no significant difference between inactive UC and healthy controls $(\mathrm{P}>0.05)$. Taken together, these results suggest that Th17 cells play an important role in the progression of UC.
Alteration of the levels of circulating Th1 and Tcl cells in patients with active and inactive UC. Th1 and Tc1 cells were identified as $\mathrm{CD} 3{ }^{+} \mathrm{CD} 8-\mathrm{IFN}-\gamma^{+}$and $\mathrm{CD} 3{ }^{+} \mathrm{CD} 8^{+} \mathrm{IFN}-\gamma^{+}$, respectively. A representative dot plot of IFN- $\gamma$ gated on $\mathrm{CD}^{+} \mathrm{T}$ cells in all the subject groups is shown in Fig. 2A. The percentage of circulating Th1 cells in the patients with active UC was significantly higher $(14.45 \pm 5.89 \%)$ than that in the patients with inactive UC $(11.27 \pm 3.34 \%, \mathrm{P}=0.002)$ and healthy controls $(9.85 \pm 1.59 \%, \mathrm{P}<0.001)$, although it was lower than that in CD $(20.64 \pm 7.22 \%, P=0.004)$. Meanwhile, the percentage of Th1 cells was higher in the patients with $C D$ than that in healthy controls $(\mathrm{P}<0.001)$ (Fig. 2B). However, there was no significant difference between inactive UC and healthy controls ( $P>0.05)$. Similarly, an increased percentage of Tc1 cells was also found in patients with active UC (14.61 $\pm 6.52 \%)$ compared with inactive UC $(11.32 \pm 3.21 \%$, $\mathrm{P}=0.013)$ and healthy controls $(10.16 \pm 2.11 \%, \mathrm{P}=0.006)$. Yet, the level of circulating Tc1 cells in CD (20.22 $27.22 \%)$ was higher than that in active $\mathrm{UC}(\mathrm{P}=0.008)$. No significant difference was observed between inactive UC and healthy controls (P>0.05) (Fig. 2C).

Correlation among Th17, Thl and Tcl cells in patients with active UC. The correlation of Th17, Th1 and Tc1 cells in UC was further investigated. As shown in Fig. 3, the percentage of circulating Th1 cells had a significant positive correlation with Th17 ( $\mathrm{r}=0.76, \mathrm{P}<0.05)$ (Fig. 3A) and Tc1 cells $(\mathrm{r}=0.55, \mathrm{P}<0.05)$ (Fig. 3B) in patients with active UC. However, no significant correlation between Th17 and Tc1 cells was observed ( $\mathrm{r}=0.11$, $\mathrm{P}>0.05$ ) (Fig. 3C). 
A

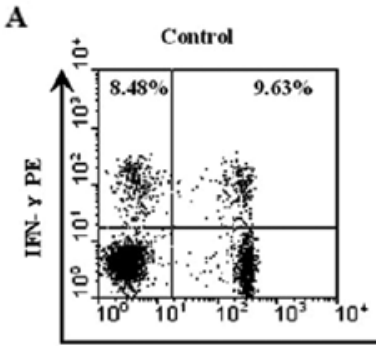

B

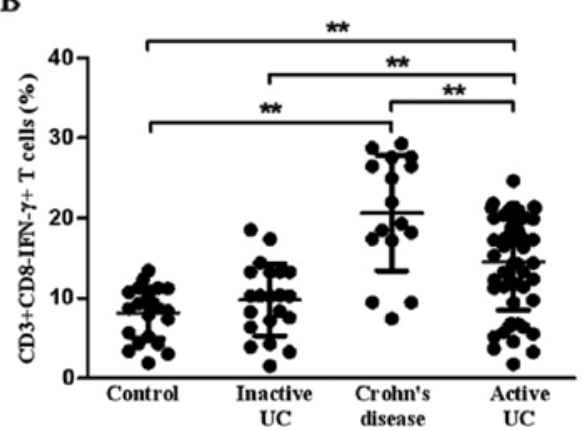

Inactive UC

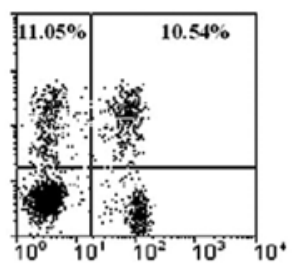

Crohn's disease

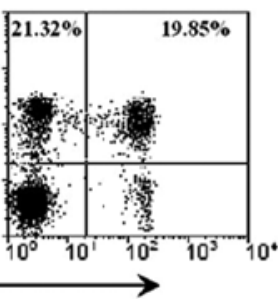

Active UC

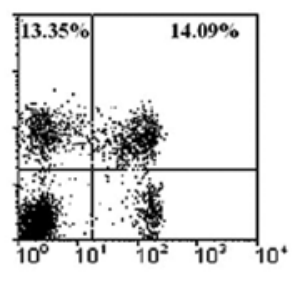

C

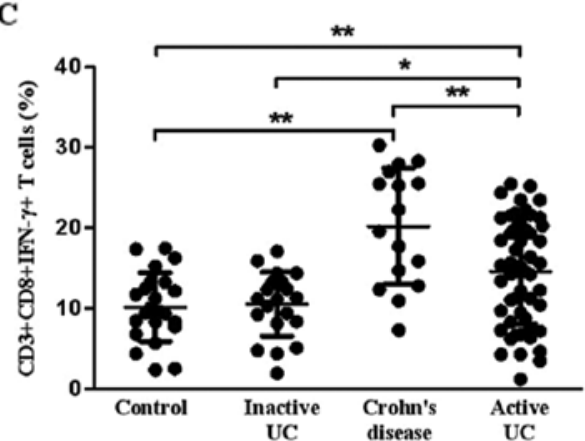

Figure 2. Expression of circulating Th1 and Tc1 cells in patients with active and inactive UC, CD and healthy controls. Heparinized peripheral whole blood from all subjects was stimulated with PMA, ionomycin and monensin for $4 \mathrm{~h}$, and then stained with labeled antibodies as described in Materials and methods. (A) Representative IFN- $\gamma$ expression in $\mathrm{CD}^{+} \mathrm{CD} 8-\mathrm{T}$ subsets (Th1, CD4 ${ }^{+} \mathrm{T}$ subsets) and $\mathrm{CD} 3^{+} \mathrm{CD}^{+} \mathrm{T}$ subsets (Tc1) from each group is shown. (B and $\mathrm{C}$ ) The level of Th1 and Tc1 cells of all subjects in the four groups. ${ }^{*} \mathrm{P}<0.05$ and ${ }^{* *} \mathrm{P}<0.01$. UC, ulcerative colitis.
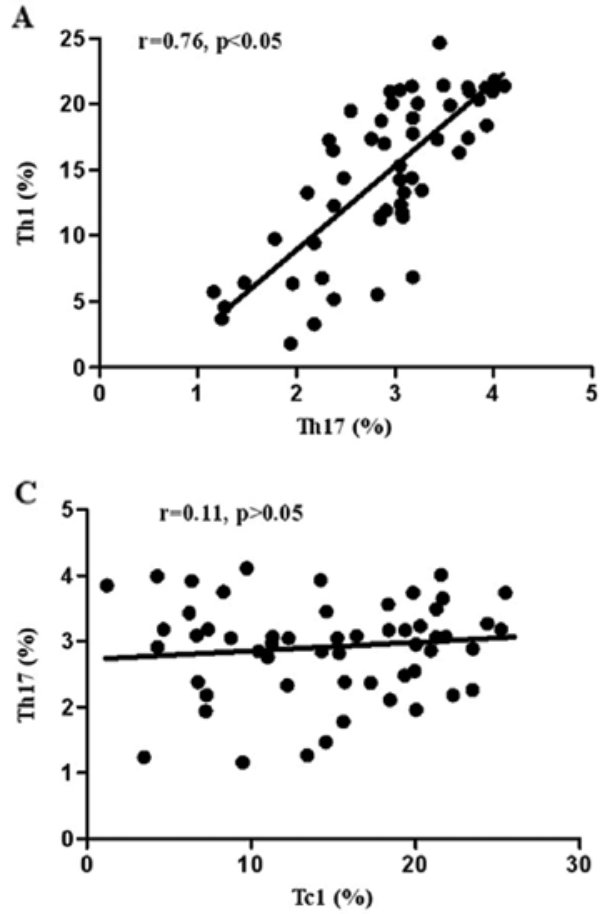

Correlation of Th17, Thl and Tcl cells with clinical parameters in patients with active UC. To investigate whether these cells were involved in UC progression, the correlation of these cells with clinical and laboratory features of patients with active UC was analyzed. As shown in Table I, the percentage of circulating Th17 and Th1 cells had a positive correlation with disease activity $(\mathrm{P}=0.007$ for Th17, $\mathrm{P}=0.014$ for Th1), extent of disease $(\mathrm{P}=0.001$ for $\mathrm{Th} 17, \mathrm{P}=0.002$ for Th1), ESR $(\mathrm{P}=0.001$ for Th17, $\mathrm{P}=0.01$ for Th1) and CRP $(\mathrm{P}=0.005$ for

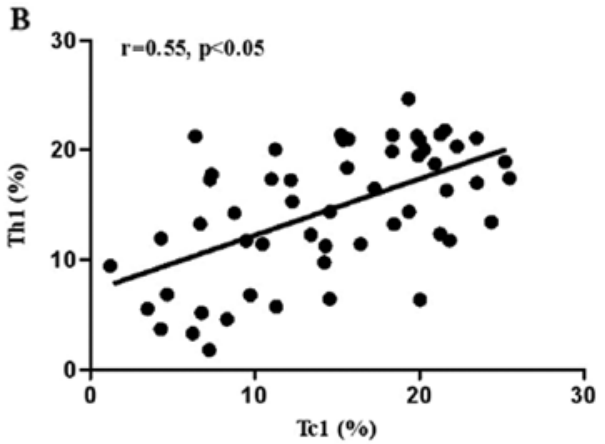

Figure 3. Correlation of Th17/Th1, Th1/Tc1 and Th17/Tc1 cells in patient with active ulcerative colitis. (A) The percentage of Th17 cells was positively correlated with the percentage of Th1 cells. (B) The percentage of Th1 cells was positively correlated with the percentage of Tc1 cells. (C) The percentage of Th17 cells had no correlation with the percentage of Tc1 cells.

Th17, $\mathrm{P}=0.001$ for Th1) in the patients with active UC, while the percentage of circulating $\mathrm{Tcl}$ cells had a correlation with disease activity of patients with active UC $(\mathrm{P}=0.014)$.

Levels of Th17 and Thl cytokines in patients with active UC, inactive $U C, C D$ and healthy controls. We further investigated the concentration of Th17 and Th1 cytokines in plasma. Fig. 4A shows that the plasma level of IL-17 was higher in patients with active UC $(17.08 \pm 6.44 \mathrm{pg} / \mathrm{ml})$ when compared with the level 
A

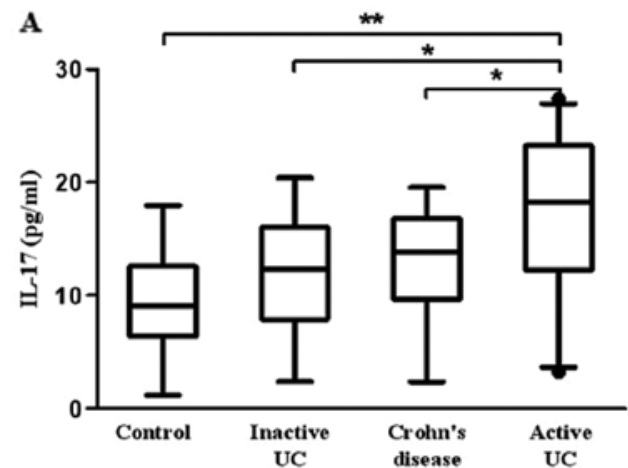

B

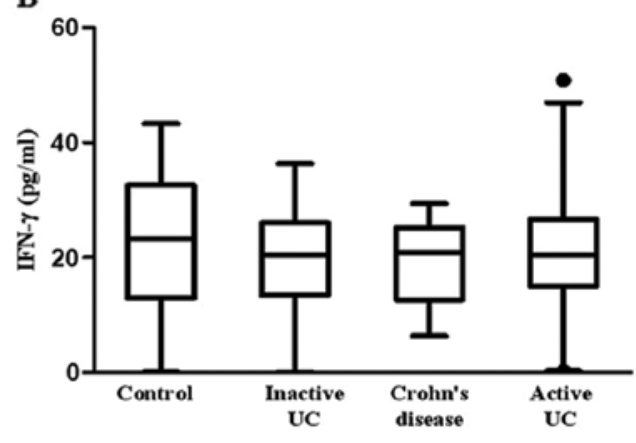

Figure 4. Expression of plasma IL-17 and IFN- $\gamma$ in patients with active UC, inactive UC, CD and healthy controls. Levels of plasma (A) IL-17 and (B) IFN- $\gamma$ were measured by ELISA in patients with active UC, inactive UC, CD and healthy controls. Each bar represents the mean $\pm \mathrm{SD}$. ${ }^{*} \mathrm{P}<0.05$ and ${ }^{* *} \mathrm{P}<0.01$. $\mathrm{UC}$, ulcerative colitis.

A

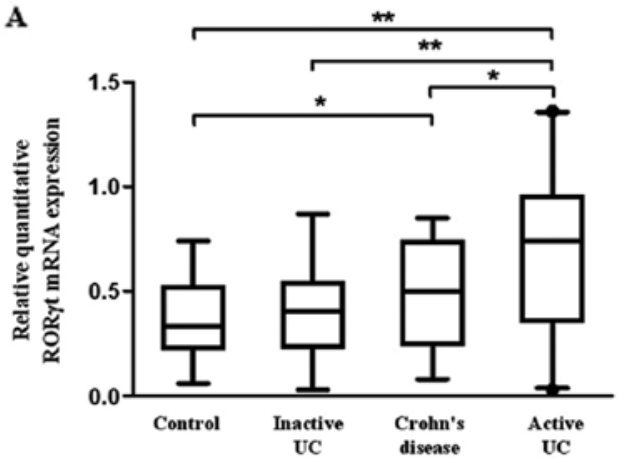

B

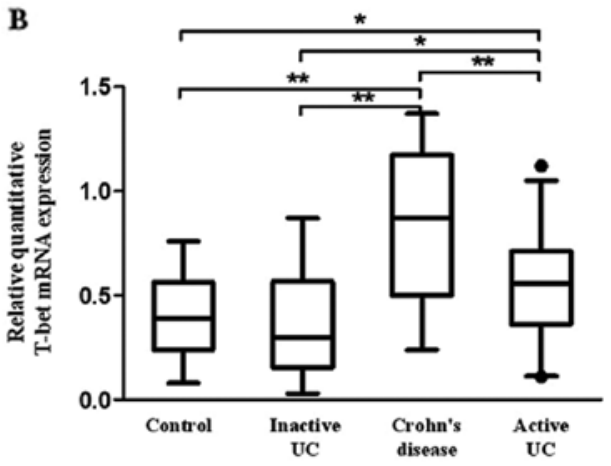

Figure 5. Expression of ROR $\gamma \mathrm{t}$ mRNA and T-bet mRNA in patients with active UC, inactive UC, CD and healthy controls. Levels of (A) ROR $\gamma \mathrm{t}$ mRNA and (B) T-bet mRNA were measured by real time-PCR in patients with active UC, inactive UC, CD and healthy controls. Each bar represents the mean \pm SD. ${ }^{*} \mathrm{P}<0.05$ and ${ }^{* *} \mathrm{P}<0.01$. UC, ulcerative colitis.

in patients with inactive UC $(12.00 \pm 4.12 \mathrm{pg} / \mathrm{ml}, \mathrm{P}=0.034), \mathrm{CD}$ $(13.12 \pm 3.07 \mathrm{pg} / \mathrm{ml}, \mathrm{P}=0.011)$ and controls $(9.46 \pm 4.34 \mathrm{pg} / \mathrm{ml}$, $\mathrm{P}=0.001)$. However, no significant difference in plasma IFN- $\gamma$ was observed between active UC $(23.14 \pm 11.72 \mathrm{pg} / \mathrm{ml})$, inactive UC $(22.57 \pm 7.82 \mathrm{pg} / \mathrm{ml}), \mathrm{CD}(20.42 \pm 7.42 \mathrm{pg} / \mathrm{ml})$ and controls $(24.09 \pm 10.39 \mathrm{pg} / \mathrm{ml})$ (Fig. 4B).

ROR $\gamma t$ and T-bet are upregulated in patients with active $U C$. Previous studies have indicated that Th1 and Th17 cell differentiation requires T-bet and $\mathrm{ROR} \gamma \mathrm{t}$, respectively (21). Therefore, we assessed the expression of T-bet and ROR $\gamma \mathrm{t}$ in PBMCs. Fig. 5A shows that the mRNA level of ROR $\gamma t$ in patients with active UC was significantly higher when compared with that in patients with inactive UC, CD and healthy controls ( $\mathrm{P}=0.020,0.011,0.001$, respectively). Moreover, a significantly increased ROR $\gamma t$ mRNA was observed in patients with CD compared with healthy controls $(\mathrm{P}=0.032)$. Similarly, T-bet mRNA was upregulated in patients with active UC compared with that in inactive UC and healthy controls, although it was lower than that in $\mathrm{CD}$ $(\mathrm{P}<0.01)$ (Fig. 5B).

Expression of STAT3 and STAT5 in patients with active $U C$, inactive $U C, C D$ and controls. STAT3 and STAT5 have been reported to play an important role in Th17 cell differentiation $(33,34)$. Here, we investigated the expression of STAT3 and STAT5 in all subjects. Our data revealed that the phosphorylation of STAT3 and STAT5 was increased in PBMCs of patients with active UC, inactive UC and CD when compared with the healthy controls $(\mathrm{P}=0.001,0.007$, 0.001 for $\mathrm{p}$-STAT3; $\mathrm{P}=0.020,0.014,0.015$ for $\mathrm{p}$-STAT5, respectively) (Fig. 6A and $\mathrm{B}$ ). To further investigate which STAT was dominant in the regulation of Th17 differentiation, we calculated the ratio of p-STAT3/p-STAT5 (Fig. 6C) and found that the ratio was higher in patients with inactive UC $(\mathrm{P}=0.021)$ and $\mathrm{CD}(\mathrm{P}=0.011)$ than that in the healthy controls. Furthermore, the ratio was higher in patients with active UC when compared with the ratio in patients with inactive UC, $\mathrm{CD}$ and healthy controls ( $\mathrm{P}=0.005,0.040,0.005$, respectively).

\section{Discussion}

Ulcerative colitis is a global health issue. Research findings in recent years has revealed that the imbalance of $\mathrm{T}$ lymphocytes plays an important role in the pathogenesis of UC (6). In the present study, our results revealed that levels of circulating Th17, Th1 and Tc1 cells were significantly increased in patients with active UC, and the percentage of Th1 cells was correlated with that of Th17 and Tc1 cells. These cells were positively correlated with disease activity or extent of disease, ESR and CRP in active UC patients. Moreover, the mRNA levels of ROR $\gamma$ t and T-bet, and the phosphorylation of STAT3 
A

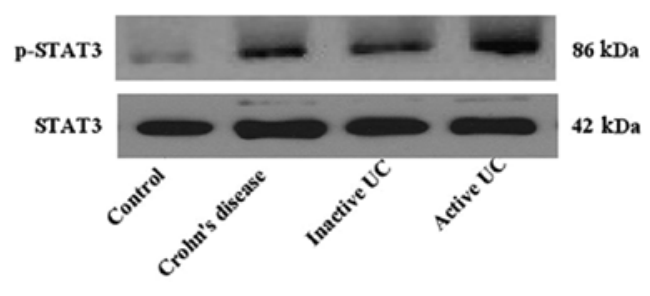

B

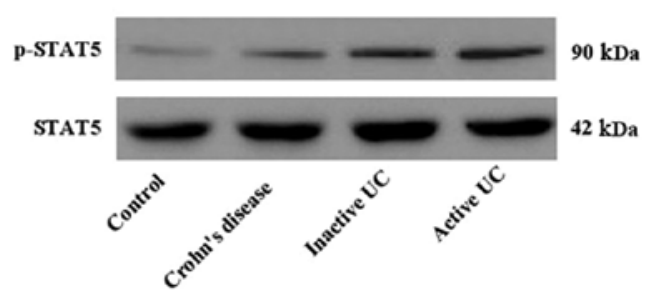

C

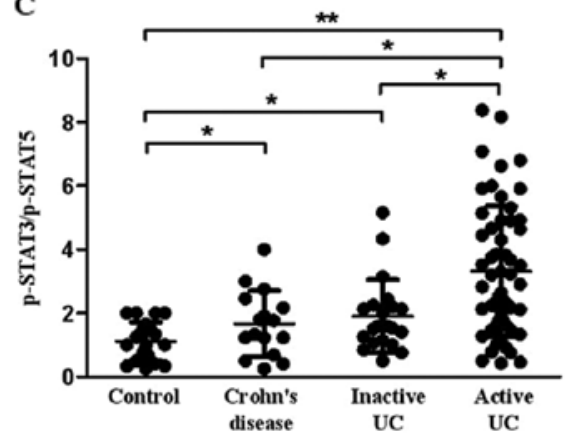

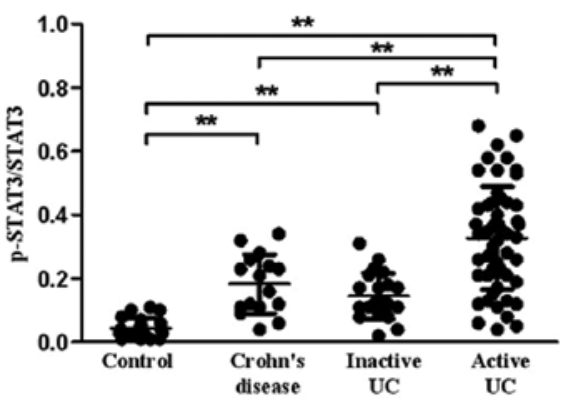

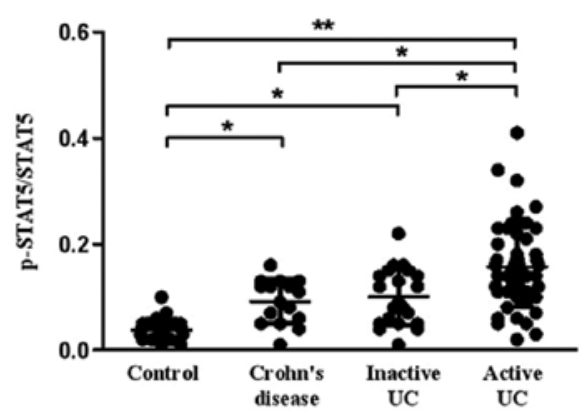

Figure 6. Expression of p-STAT3 and p-STAT5 in patients with active UC, inactive UC, CD and healthy controls. The expression levels of (A) p-STAT3 and (B) p-STAT5 in PBMCs were determined by western blotting in patients with active UC, inactive UC, CD and healthy controls. One representative sample is shown. Graphs show the quantitation of STAT3 and STAT5, respectively. (C) The ratio of $\mathrm{p}$-STAT3/p-STAT5 was calculated. ${ }^{*} \mathrm{P}<0.05$ and ${ }^{* *} \mathrm{P}<0.01$. UC, ulcerative colitis.

extent of disease, ESR and CRP in active UC patients. These results indicate that UC may be characterized by a mixed profile rather than a Th2 cytokine profile, which may help to advance our understanding of the immune status of UC.

IL-17 is an $20-\mathrm{kDa}$ glycoprotein of 155 amino acids. It has been reported that IL-17 induces pro-inflammatory cytokine production by macrophages, which subsequently creates a link between innate and adaptive immunity (35). IL-17 is theoretically prone to Th17 differentiation and averse to Treg cell differentiation, and plays a role in host defense against bacteria and fungi (19). A previous study showed that IL-17 expression is correlated with increased Th1 cells in the pathogenesis of IgG4-related sclerosing sialadenitis (36). To date, information is scarce concerning the precise profile of circulating Th17 and Th1 cells, and the cytokines generated by them in the whole blood of UC patients. Our findings revealed that levels of circulating Th17 and Th1 cells in active UC patients were significantly upregulated, which is consistent with the fact that elevated expression of IFN- $\gamma$ and Th17 cytokine genes in mucosa was found to be positively correlated with the disease activity of UC $(9,37)$. We further found that the elevated levels of Th17 and Th1 cells were positively correlated with disease activity and extent, plasma CRP and ESR level, and laboratory parameters that are commonly utilized to reflect disease activity of active UC $(30,38)$. Moreover, the percentage of circulating Th17 was higher in active UC than that in CD, to T-bet mRNA in these groups. Further analysis showed that Th1 cells were positively associated with disease activity and 
although the cytokine profile of $\mathrm{CD}$ is characterized by a Th1 pattern (39). All of these data suggest that Th1 and Th17 cells play an important role in the development and progression of $\mathrm{UC}$, and their close relationship with clinical parameters and laboratory features implicate a potential parameter for the diagnosis and differential diagnosis of UC. Further studies involving a greater number of patients may clarify their usefulness in UC.

Th17 cell differentiation requires the activity of ROR $\gamma \mathrm{t}$, one subtype of ROR $\gamma$ (21). Our results revealed that the mRNA level of ROR $\gamma \mathrm{t}$ in PBMCs was increased in active UC when compared with levels in inactive $\mathrm{UC}$ and $\mathrm{CD}$. A previous study demonstrated that immune-deficient (RAG1-deficient) mice receiving $\mathrm{T}$ cells transferred from ROR $\gamma \mathrm{t}$-deficient mice, which lack a transcription factor necessary for production of Th17 cytokines (ie, IL-17A, IL-17F or IL-22), failed to develop colitis (40). Notably, when treated with exogenous IL-17A, mice may develop colitis, suggesting that ROR $\gamma \mathrm{t}$ plays a preliminary role to IL-17 in the development of UC. This hypothesis is also supported by a further experimental model. RAG1-deficient mice that received T cells with normal ROR $\gamma \mathrm{t}$ expression but lacking the capacity to produce the individual Th17 cytokine presented with full-blown colitis (40). It has been reported that when appropriate stimuli (such as IL-12) exist, then cells of the Th17 lineage are plastic and differentiate into Th1-type cells (41). Thus, one possible explanation is that transfer of ROR $\gamma t$-deficient $\mathrm{T}$ cells may lead to a great reduction in IFN- $\gamma$ production, and consequently induce the development of UC. These studies provide a basic framework with which to understand the immunopathogenesis of UC. In addition, several upregulated inflammatory factors in patients with UC, such as IL-6, TGF- $\beta$ and IL-23, may induce ROR $\gamma \mathrm{t}$ expression $(13,23)$. However, their expression levels were not explored in this study.

Cytokine signaling pathways involving transcription factors of the STAT family play a key role in the pathogenesis of UC. STAT proteins are latent cytoplasmic transcription factors that induce transcription upon phosphorylation, dimerization and nuclear translocation (25). As two major members of the STAT family, the relative activation of STAT3 and STAT5 directly dictates the outcome of IL-17 production (42). Our results demonstrated that the level of p-STAT3 was higher in patients with active UC when compared with the level in patients with inactive UC. This is consistent with observations that upregulation of STAT3 is associated with aggravation of UC (25). Notably, in the present study, the level of p-STAT5 was also increased, although it has been reported that action of STAT5 mediated by IL-2 opposes Th17 cell differentiation (34). This may be because STAT5 is also expressed in other blood cells, such as B cells and CD8 ${ }^{+}$ $\mathrm{T}$ cells (43). Further experiments must be design to analyze the expression of STAT5 in different subgroups of T cells. However, the ratio of p-STAT3/p-STAT5 was higher in active UC patients than that in inactive UC and healthy controls, thereby suggesting that STAT3 is predominant in active UC. The ratio was still higher in patients with inactive UC when compared with the ratio in the controls and this may be a reason for the relapse of UC. Taken together, our findings indicate that i) STAT3, but not STAT5, predominates in the progression of UC, and ii) the role of the STAT family in Th17 cells are disease specific. In addition, the JAK-STAT pathway and activated STAT3, induced by IL-6, IL-21 and IL-23, are implicated in Th17 differentiation and function by binding to the IL-17A promoter directly as shown by ChIP, and are regarded as a critical component of Th17-dependent autoimmune processes $(22,23)$. This suggests that other molecules may be required for this process, and further experiments are required to test these possibilities.

Plasma IL-17 and IFN- $\gamma$ levels were also evaluated in our study. IL-17 was elevated in active UC, and these results are compatible with flow cytometric data. Notably, our findings showed that plasma IL-17 was higher in active UC than in CD. However, Fujino et al (44) revealed that IL-17 is higher in $\mathrm{CD}$ than in UC. This discrepancy is possibly due to the ethnic distinction or the differences in procedure and patients in our experiments. Notably, there was no significant difference in plasma IFN- $\gamma$ expression, although a difference was observed by flow cytometry. The reason may be due to the fact that: i) cytokines in the plasma were at a low level; ii) the cells measured by flow cytometry were stimulated with PMA and ionomycin while the blood used for ELISA was not treated as described in Materials and methods; and iii) the methods used had different sensitivities, i.e., flow cytometry may be more sensitive than ELISA.

Our findings suggest that levels of circulating Tc1 cells are also increased in UC and are positively related to Th1 cells, which is in line with a previous study that found that the predominance of $\mathrm{Th} 1$ and $\mathrm{Tc} 1$ cells contributes to the pathogenic mechanism in IgG4-related sclerosing sialadenitis (36). This indicates that Tc cell-mediated cytotoxicity is an alternative mechanism for active UC, and that predominant Tc1 cells, probably accompanying a Th1 response, may play a cooperative or synergetic function through production of IFN- $\gamma$ under the influence of a particular microenvironment. This is in line with previous findings that IFN- $\gamma$-producing $\mathrm{CD} 8^{+}$lymphocytes are increased in the PBMCs of patients with UC by co-incubation with epithelial cells (45). In addition, an aberrant T-cell function has been indicated in UC with abnormal cytokine profiles correlated to loss of immune tolerance (46). A detailed phenotypic and functional analysis of this subset is warranted.

In conclusion, elevated levels of circulating Th17, Th1 and Tc1 cells, as well as abnormal activity of the STAT pathway, may be implicated in the progression of UC. Our findings may help to broaden our understanding of the immunopathological role of circulating $\mathrm{T}$ lymphocytes in the progression of UC.

\section{Acknowledgements}

The study was supported by the China National Natural Science Foundation Projects (grant nos. 81271916, 31270971, 81072406 and 30672010) and the Graduate Independent Innovation Foundation of Shandong University (grant no. yzc10133). The authors thank Dr Edward C. Mignot, Shandong University, for linguistic advice.

\section{References}

1. Wang YF, Ouyang Q and Hu RW: Progression of inflammatory bowel disease in China. J Dig Dis 11: 76-82, 2010. 
2. Eaden JA, Abrams KR and Mayberry JF: The risk of colorectal cancer in ulcerative colitis: a meta-analysis. Gut 48: 526-535, 2001.

3. Choi PM and Zelig MP: Similarity of colorectal cancer in Crohn's disease and ulcerative colitis: implications for carcinogenesis and prevention. Gut 35: 950-954, 1994.

4. Targan SR and Karp LC: Defects in mucosal immunity leading to ulcerative colitis. Immunol Rev 206: 296-305, 2005.

5. Ishiguro Y: Mucosal proinflammatory cytokine production correlates with endoscopic activity of ulcerative colitis. J Gastroenterol 34: 66-74, 1999.

6. Strober W and Fuss IJ: Proinflammatory cytokines in the pathogenesis of inflammatory bowel diseases. Gastroenterology 140: 1756-1767, 2011

7. Melgar S, Yeung MM, Bas A, et al: Over-expression of interleukin 10 in mucosal $\mathrm{T}$ cells of patients with active ulcerative colitis. Clin Exp Immunol 134: 127-137, 2003.

8. Strober W, Fuss IJ and Blumberg RS: The immunology of mucosal models of inflammation. Annu Rev Immunol 20 . 495-549, 2002

9. Rismo R, Olsen T, Cui G, Christiansen I, Florholmen J and Goll R: Mucosal cytokine gene expression profiles as biomarkers of response to infliximab in ulcerative colitis. Scand J Gastroenterol 47: 538-547, 2012.

10. Komatsu M, Kobayashi D, Saito K, et al: Tumor necrosis factoralpha in serum of patients with inflammatory bowel disease as measured by a highly sensitive immuno-PCR. Clin Chem 47: 1297-1301, 2001

11. Akazawa A, Sakaida I, Higaki S, Kubo Y, Uchida K and Okita K: Increased expression of tumor necrosis factor-alpha messenger RNA in the intestinal mucosa of inflammatory bowel disease, particularly in patients with disease in the inactive phase. J Gastroenterol 37: 345-353, 2002.

12. Olsen T, Goll R, Cui G, et al: Tissue levels of tumor necrosis factor-alpha correlates with grade of inflammation in untreated ulcerative colitis. Scand J Gastroenterol 42: 1312-1320, 2007.

13. Bernardo D, Vallejo-Díez S, Mann ER, et al: IL-6 promotes immune responses in human ulcerative colitis and induces a skin-homing phenotype in the dendritic cells and $\mathrm{T}$ cells they stimulate. Eur J Immunol 42: 1337-1353, 2012.

14. Rovedatti L, Kudo T, Biancheri P, et al: Differential regulation of interleukin 17 and interferon gamma production in inflammatory bowel disease. Gut 58: 1629-1636, 2009.

15. Zhang J, Ma D, Zhu X, Qu X, Ji C and Hou M: Elevated profile of Th17, Th1 and Tc1 cells in patients with immune thrombocytopenic purpura. Haematologica 94: 1326-1329, 2009.

16. Zhang L, Li JM, Liu XG, et al: Elevated Th22 cells correlated with Th17 cells in patients with rheumatoid arthritis. J Clin Immunol 31: 606-614, 2011.

17. Harrington LE, Hatton RD, Mangan PR, et al: Interleukin 17-producing $\mathrm{CD}^{+}$effector $\mathrm{T}$ cells develop via a lineage distinct from the Thelper type 1 and 2 lineages. Nat Immunol 6 : 1123-1132, 2005

18. Park H, Li Z, Yang XO, et al: A distinct lineage of CD4 T cells regulates tissue inflammation by producing interleukin 17 . Nat Immunol 6: 1133-1141, 2005.

19. Monteleone I, Pallone F and Monteleone G: Th17-cytokine blockers as a new approach for treating inflammatory bowel disease. Ann Med 43: 172-178, 2011.

20. Bettelli E, Korn T, Oukka M and Kuchroo VK: Induction and effector functions of T(H)17 cells. Nature 453: 1051-1057, 2008.

21. Ivanov, II, McKenzie BS, Zhou L, et al: The orphan nuclear receptor RORgammat directs the differentiation program of proinflammatory $\mathrm{IL}-17^{+} \mathrm{T}$ helper cells. Cell 126: 1121-1133, 2006.

22. Li Y, de Haar C, Chen M, et al: Disease-related expression of the IL6/STAT3/SOCS3 signalling pathway in ulcerative colitis and ulcerative colitis-related carcinogenesis. Gut 59: 227-235, 2010.

23. Bi Y and Yang R: Direct and indirect regulatory mechanisms in TH17 cell differentiation and functions. Scand J Immunol 75 543-552, 2012.

24. Monteleone I, Pallone F and Monteleone G: Th17-related cytokines: new players in the control of chronic intestinal inflammation. BMC Med 9: 122, 2011.

25. Li F, Zou Y and Li X: Up-regulation of signal transducer and activator of transcription-3 is associated with aggravation of ulcerative colitis. Surgeon 8: 262-266, 2010.
26. Sandborn WJ and Faubion WA: Biologics in inflammatory bowel disease: how much progress have we made? Gut 53: 1366-1373, 2004

27. Sands BE: From symptom to diagnosis: clinical distinctions among various forms of intestinal inflammation. Gastroenterology 126: 1518-1532, 2004.

28. Schroeder KW, Tremaine WJ and Ilstrup DM: Coated oral 5-aminosalicylic acid therapy for mildly to moderately active ulcerative colitis. A randomized study. N Engl J Med 317: 1625-1629, 1987.

29. Hart AL, Kamm MA, Knight SC and Stagg AJ: Prospective evaluation of intestinal homing memory $\mathrm{T}$ cells in ulcerative colitis. Inflamm Bowel Dis 10: 496-503, 2004.

30. Bitton A, Peppercorn MA, Antonioli DA, et al: Clinical, biological, and histologic parameters as predictors of relapse in ulcerative colitis. Gastroenterology 120: 13-20, 2001.

31. Ge J, Wang K, Meng QH, Qi ZX, Meng FL and Fan YC: Implication of Th17 and Th1 cells in patients with chronic active hepatitis B. J Clin Immunol 30: 60-67, 2010.

32. Pelchen-Matthews A, Parsons IJ and Marsh M: Phorbol esterinduced downregulation of CD4 is a multistep process involving dissociation from p56lck, increased association with clathrincoated pits, and altered endosomal sorting. J Exp Med 178: 1209-1222, 1993

33. Yang XP, Ghoreschi K, Steward-Tharp SM, et al: Opposing regulation of the locus encoding IL-17 through direct, reciprocal actions of STAT3 and STAT5. Nat Immunol 12: 247-254, 2011.

34. Laurence A, Tato CM, Davidson TS, et al: Interleukin-2 signaling via STAT5 constrains T helper 17 cell generation. Immunity 26: 371-381, 2007.

35. Kolls JK and Lindén A: Interleukin-17 family members and inflammation. Immunity 21: 467-476, 2004.

36. Ohta N, Makihara S, Okano M, et al: Roles of IL-17, Th1, and $\mathrm{Tc1}$ cells in patients with IgG4-related sclerosing sialadenitis. Laryngoscope 122: 2169-2174, 2012.

37. Olsen T, Rismo R, Cui G, Goll R, Christiansen I and Florholmen J: TH1 and TH17 interactions in untreated inflamed mucosa of inflammatory bowel disease, and their potential to mediate the inflammation. Cytokine 56: 633-640, 2011.

38. Turner D, Mack DR, Hyams J, et al: C-reactive protein (CRP), erythrocyte sedimentation rate (ESR) or both? A systematic evaluation in pediatric ulcerative colitis. J Crohns Colitis 5: 423-429, 2011

39. Dong C: TH17 cells in development: an updated view of their molecular identity and genetic programming. Nat Rev Immunol 8: 337-348, 2008

40. Leppkes M, Becker C, Ivanov II, et al: RORgamma-expressing Th17 cells induce murine chronic intestinal inflammation via redundant effects of IL-17A and IL-17F. Gastroenterology 136: 257-267, 2009.

41. Boniface K, Blumenschein WM, Brovont-Porth K, et al: Human Th17 cells comprise heterogeneous subsets including IFN- $\gamma$-producing cells with distinct properties from the Th1 lineage. J Immunol 185: 679-687, 2010.

42. Garg SK, Voelmle MK, Beatson CR, et al: Use of continuous glucose monitoring in subjects with type 1 diabetes on multiple daily injections versus continuous subcutaneous insulin infusion therapy: a prospective 6-month study. Diabetes Care 34: 574-579, 2011

43. Johnston RJ, Choi YS, Diamond JA, Yang JA and Crotty S: STAT5 is a potent negative regulator of TFH cell differentiation. J Exp Med 209: 243-250, 2012.

44. Fujino S, Andoh A, Bamba S, et al: Increased expression of interleukin 17 in inflammatory bowel disease. Gut 52: 65-70, 2003.

45. Bisping G, Lugering N, Lutke-Brintrup S, et al: Patients with inflammatory bowel disease (IBD) reveal increased induction capacity of intracellular interferon-gamma (IFN-gamma) in peripheral $\mathrm{CD} 8^{+}$lymphocytes co-cultured with intestinal epithelial cells. Clin Exp Immunol 123: 15-22, 2001.

46. Kamikozuru K, Fukunaga K, Hirota S, et al: The expression profile of functional regulatory T cells, $\mathrm{CD} 4{ }^{+} \mathrm{CD} 25^{\text {hight }} /$ forkhead box protein $\mathrm{P}^{+}$, in patients with ulcerative colitis during active and quiescent disease. Clin Exp Immunol 156: 320-327, 2009. 